\title{
Probabilistic identification of soil stratification
}

\author{
J. LI*, M. J. CASSIDY†, J. HUANG $\ddagger$ L. ZHANG§ and R. KELLY
}

\begin{abstract}
Identification of soil stratification is vital to geotechnical structural design and construction where the soil layer, soil type and properties are necessary inputs. Although methods are available for classifying the soil profiling using measured cone penetration test (CPT) data, the identification of soil stratification at unsampled locations is still difficult due to significant variability of natural soil. The identification is further complicated by the considerable uncertainties in the CPT measurements and soil classification methods. This study aims to develop a probabilistic method to predict soil stratification at unsampled locations by explicitly filtering the uncertainties in soil classification systems. An established Kriging interpolation technique is used to estimate the CPT parameters which are further interpreted to identify the soil stratification. Equations are derived to quantify the degree of uncertainties reduced by this method. The approaches are illustrated using a database of 26 CPT tests recently sourced from a dike near Ballina, Australia. Results show that the majority of the uncertainties in the soil parameters are screened by a soil classification index. The remaining uncertainties are further filtered by the soil classification systems. A clear stratification with a high degree of confidence is obtained in both horizontal plane and vertical unsampled locations, which shows excellent agreement with the existing CPT tests. This study provides a methodology to clearly identify the soil strata and reduce the uncertainties in prediction of design properties, paving the way for a more cost-effective geotechnical design.
\end{abstract}

KEYWORDS: geology; site investigation; soil classification; statistical analysis

\section{INTRODUCTION}

Soil stratification is essential in geotechnical site characterisation and structural design (Houlsby \& Houlsby, 2013; Wang et al., 2014). Recent studies have reported the significant effect of soil stratification on the design of foundations, tunneling and pipelines (Burd \& Frydman, 1997; Padrón et al., 2008; Huang \& Griffiths, 2010; Zhang et al., 2012; Lee et al., 2013; White et al., 2014). The identification of soil stratification includes determining soil types, the number of soil layers, the thickness of each layer and soil properties.

The standardised cone penetration test (CPT) and piezocone (CPTU) have been widely used to infer the soil type by directly interpreting measured CPT/CPTU parameters (e.g. Schmertmann, 1978; Douglas \& Olsen, 1981; Robertson \& Campanella, 1983; Robertson, 1990; Jefferies \& Davies, 1993; Olsen \& Mitchell, 1995; Eslami \& Fellenius, 1997; Lunne et al., 1997; Schneider et al., 2008). Hence, the identity of the soil type can only be obtained at the location at which a CPT is conducted. When the soil stratification at nearby locations is required during a design or construction process, the results at the existing location generally cannot be used directly due to the significant variability of natural

Manuscript received 27 November 2014; revised manuscript accepted 2 July 2015. Published online ahead of print 16 September 2015.

Discussion on this paper closes on 1 June 2016, for further details see p. ii.

* Centre for Offshore Foundation Systems and ARC CoE for Geotechnical Science and Engineering, University of Western Australia, Crawley, Australia.

$\dagger$ Lloyd's Register Foundation Chair of Offshore Foundations, Centre for Offshore Foundation Systems and ARC CoE for Geotechnical Science and Engineering, University of Western Australia, Crawley, Australia.

\$ ARC CoE for Geotechnical Science and Engineering, University of Newcastle, Newcastle, Australia.

$\S$ Department of Civil and Environmental Engineering, The Hong Kong University of Science and Technology, Hong Kong. soils (Lloret-Cabolt et al., 2014). The stratification of natural soil may change greatly within a small horizontal distance of, say, $15 \mathrm{~m}$ (Das, 2010). The evaluation of soil stratification at unsampled locations with no available data remains an unsolved problem.

EN 1990 (CEN, 2002) provides a method for the calibration of partial factors, which, however, cannot be used to estimate parameters at unsampled locations. The maximum likelihood method can be used to estimate the optimal value of a parameter of interest by maximising the likelihood function or the chance for observing the data. This maximum likelihood method assumes that the observations are statistically independent; ignoring the inherent correlation among the observations. The interpolation technique can give a rough estimation of a certain soil parameter at unsampled locations based on existing CPT data (Lacasse \& Nadim, 1996; Beacher \& Christian, 2003). Traditional interpolation techniques that approximate the variable of interest by a specified function (e.g. polynomials) cannot accommodate the correlations among the CPT data. Kriging is a probabilistic-based approach that produces an interpolation function based on a variogram model derived from the data rather than a prior model of the interpolating function (Chilès \& Delfiner, 2012). This estimation will inevitably vary over a wide range due to the considerable variability of CPT measurements as well as the uncertainties associated with soil classification methods (e.g. Zhang \& Tumay, 1999; Kurup \& Griffin, 2006; Jung et al., 2008; Cetin \& Ozan, 2009; Wang et al., 2013). Therefore, clear determination of soil stratification from a scattered and obscured estimation of soil parameters is difficult (Houlsby \& Houlsby, 2013).

This study aims to predict soil stratification at unsampled locations by explicitly filtering the uncertainties in soil classification systems. Considering the spatial variability of existing CPTU tests, estimates of soil parameters at locations of interest are first obtained, with their variations clearly demonstrated. The uncertainties that propagate from this 
estimation to the soil stratification are then significantly reduced through a soil classification system. Ultimately, a clear soil stratification in three dimensions is identified with a limited number of CPTU tests.

\section{KRIGING ESTIMATION AT UNSAMPLED LOCATIONS}

Kriging is an advanced interpolation procedure that uses the correlation among existing data (Matheron, 1971). The correlation is often described by a semivariogram, the value of which for separation distance $h$ is calculated by the average squared difference in property values between pairs of input sample points separated by $h$

$$
\gamma_{h}=\frac{1}{2} E\left[\left(p_{i}-p_{i+h}\right)^{2}\right]
$$

where $\gamma_{h}$ is the semivariogram value for the data pairs with property values of $p_{i}$ and $p_{i+h}$. In geotechnical practice, CPT locations are often irregularly spaced, requiring the distance and directions to be grouped into subsets (Olea, 1999; Dasaka \& Zhang, 2012) and for the semivariogram to be evaluated based on the subsets. To evaluate the spatial variability using Kriging techniques it is essential that the data are stationary; that is, the mean and covariance of the data depend only upon separation, not on absolute location. If the semivariogram does not level off for long separation distances, this indicates that the data set is non-stationary (Kulatilake \& Ghosh, 1988). If the data are non-stationary, treatment must be given to transform the data to a stationary set by removing the deterministic component called the trend, and the stationary residual random component is then analysed.

The properties at an unsampled location can be estimated using a linear weighting of all measured data within the effective domain around the location

$$
\hat{p}_{0}=\sum_{i=1}^{N} \lambda_{i} p_{i}
$$

where $\lambda_{i}$ is the weight for the measured property $p_{i}$, and $\hat{p}_{0}$ is the estimated property at the unsampled location. Kriging uses the semivariogram to assign a weight to each measured data point. To ensure the estimated value is unbiased, the sum of the weights $\lambda_{i}$ must equal to one. The weights are selected to minimise the expected mean squared error between the estimation and the true value. The solution to the minimisation, constrained by the unbiased estimation, gives the Kriging equations (Murakami et al., 2006)

$$
\left[\begin{array}{cccc}
\gamma_{11} & \cdots & \gamma_{1 N} & 1 \\
\vdots & \ddots & \vdots & \vdots \\
\gamma_{N 1} & \cdots & \gamma_{N N} & 1 \\
1 & \cdots & 1 & 0
\end{array}\right] \cdot\left[\begin{array}{c}
\lambda_{1} \\
\vdots \\
\lambda_{N} \\
m
\end{array}\right]=\left[\begin{array}{c}
\gamma_{10} \\
\vdots \\
\gamma_{N 0} \\
1
\end{array}\right]
$$

where $\gamma_{i j}$ denotes the modelled semivariogram values based on the distance between the two samples pertaining to the $i$ th and $j$ th locations. The unknown $m$ is a Lagrange multiplier to ensure the unbiased constraint.

The semivariogram can be evaluated using nugget (i.e. a small offset of the semivariance when the separation is zero), range (i.e. the distance where the model first flattens out) and sill (i.e. the value that the semivariogram model attains at the range). If a high-quality semivariogram with a small nugget/ sill ratio and a large range is obtained, Kriging can be performed with only a few data (Jernigan, 1986). An important parameter to quantify the accuracy of the estimation is the Kriging variance $\left(\sigma^{2}\right)$

$$
\sigma^{2}=E\left(\hat{p}_{0}-p_{0}\right)^{2}
$$

where $\sigma$ is the Kriging standard error. This Kriging variance depends only on the locations of the data but not on their values. To measure the relative variation of the estimation, a Kriging variation is defined as

$$
\varepsilon=\frac{\sigma}{\hat{p}_{0}}
$$

The quality of semivariogram affects the Kriging variation, an indicator measuring the estimation accuracy. Both the quality of semivariogram and the Kriging variation are dependent on the following aspects.

(a) CPT plan and data quality. The distances between the CPTs and the number of CPTs are essential to the estimation. If the distances between the CPTs are larger than the correlation length, the correlation structure cannot be obtained properly, which directly influences the accuracy of the estimation. High-quality data that lead to a small nugget and a large range in the semivariogram maintain small measurement errors and give better estimation.

(b) Correlation of existing data. Good correlation of the existing data results in a good estimation of the semivariogram, which, in turn, leads to a small Kriging variation.

(c) Distance between the location of interest and existing CPTs. As the estimation relies more heavily on neighbouring CPTs, the accuracy is better in the vicinity of existing tests.

(d) Estimated value of the property. Kriging variance is dependent on location and correlation structure, which are not related to the estimated value of the property. However, the Kriging variation is a value relative to the estimated value, which depends on the estimated value. If the estimated value is relatively small, its Kriging variation tends to be large.

The range within which the true value of the estimated property lies with a prescribed probability is often of practical interest. This range (with lower and upper limits) can be defined by assuming a normally distributed parameter with a mean value of $\hat{p}_{0}$ and a variance of $\sigma^{2}$ (Ang \& Tang, 2007)

$$
\left\langle p_{0}\right\rangle_{1-\alpha}=\left(\hat{p}_{0}+k_{\alpha / 2} \sigma ; \hat{p}_{0}+k_{(1-\alpha / 2)} \sigma\right)
$$

in which $\left\langle p_{0}\right\rangle_{1-\alpha}$ is the $(1-\alpha)$ confidence interval for the estimation, $k_{\alpha / 2}=-\Phi^{-1}(1-\alpha / 2)$ and $k_{(1-\alpha / 2)}=\Phi^{-1}(1-\alpha / 2)$. $\Phi$ is the cumulative distribution function of the standard normal variate. $\alpha$ is a parameter to specify the probability. Particularly, the $95 \%$ confidence interval (with $\alpha$ equal to $0.05)$ of the estimation is $\left(\hat{p}_{0}-1.96 \sigma ; \hat{p}_{0}+1.96 \sigma\right)$.

\section{UNCERTAINTY IN SOIL CLASSIFICATION BASED ON CPTU TESTS}

The soil classification method proposed by Robertson (1990) is one of the most widely used methods and adopts three parameters based on CPTU tests

(a) normalised cone resistance

$$
Q_{\mathrm{t}}=\frac{q_{\mathrm{t}}-\sigma_{\mathrm{v} 0}}{\sigma_{\mathrm{v} 0}^{\prime}}
$$


(b) normalised friction ratio

$$
F_{\mathrm{R}}=\frac{f_{\mathrm{s}}}{q_{\mathrm{t}}-\sigma_{\mathrm{v} 0}} \times 100 \%
$$

(c) pore pressure ratio

$$
B_{\mathrm{q}}=\frac{u-u_{0}}{q_{\mathrm{t}}-\sigma_{\mathrm{v} 0}^{\prime}}
$$

where $\sigma_{\mathrm{v} 0}$ is total overburden stress, $\sigma_{\mathrm{v} 0}^{\prime}$ is effective overburden stress, $f_{\mathrm{s}}$ is sleeve friction, $u$ is pore pressure measured between the cone tip and the friction sleeve, $u_{0}$ is equilibrium pore pressure, $q_{\mathrm{t}}$ is corrected cone penetration resistance to account for unequal end area effects

$$
q_{\mathrm{t}}=q_{\mathrm{c}}+(1-a) u
$$

where $q_{\mathrm{c}}$ is measured cone penetration resistance, $a$ is the net area ratio between load cell support diameter, $d$, and cone diameter, $D$

$$
a=\frac{d^{2}}{D^{2}}
$$

A soil classification chart using these three parameters was proposed by Robertson (1990). This method was further improved by Jefferies \& Davies (1993) to make the chart more amendable to spreadsheet analysis by introducing a soil classification index, $I_{\mathrm{c}}$, to define the boundary of soil type

$$
I_{\mathrm{c}}=\sqrt{\left\{3-\log \left[Q_{\mathrm{t}}\left(1-B_{\mathrm{q}}\right)\right]\right\}^{2}+\left[1 \cdot 5+1 \cdot 3\left(\log F_{\mathrm{R}}\right)\right]^{2}}
$$

Within this classification, soil types are attributed from $I_{\mathrm{c}}$, as summarised in Table 1. This CPT classification method may not provide accurate predictions of soil type based on grain size distribution but provides a guide to soil behaviour type (Lunne et al., 1997). This classification inevitably contains uncertainties, such as measurement errors and transformation uncertainty. Experience has shown that measurement errors are mainly from the measurement of cone penetration resistance $\left(q_{\mathrm{c}}\right)$, sleeve friction $\left(f_{\mathrm{s}}\right)$ and pore pressure $(u)$.

In the following sections, the cone penetration resistance, sleeve friction and pore pressure are interpolated separately at locations of interest, which quantify the variation in each parameter. The soil types are examined using the soil classification method proposed by Jefferies \& Davies (1993) based on inferred parameters. The transformation uncertainty can then be expressed in an explicit manner. In the next section, equations will be derived to quantify the uncertainties that are filtered by soil classification.

\section{UNCERTAINTY FILTERING THROUGH SOIL CLASSIFICATION}

The change in soil classification index, $\Delta I_{\mathrm{c}}$, can be expressed in terms of changes in normalised cone resistance

Table 1. Soil behaviour types from classification index, $I_{c}$ (after Jefferies \& Davies, 1993)

\begin{tabular}{l|c|l}
\hline CPTU index, $I_{\mathrm{c}}$ & Zone & Soil classification \\
\hline$I_{\mathrm{c}}<1 \cdot 25$ & 7 & Gravelly sands \\
$1 \cdot 25<I_{\mathrm{c}}<1 \cdot 90$ & 6 & Sands - clean sand to silty sand \\
$1 \cdot 90<I_{\mathrm{c}}<2 \cdot 54$ & 5 & Sand mixture - silty sand to sandy silt \\
$2 \cdot 54<I_{\mathrm{c}}<2 \cdot 82$ & 4 & Silt mixture - clayey silt to silty clay \\
$2 \cdot 82<I_{\mathrm{c}}<3 \cdot 22$ & 3 & Clays \\
$I_{\mathrm{c}}>3 \cdot 22$ & 2 & Organic clays \\
\hline
\end{tabular}

$\left(\Delta Q_{\mathrm{t}}\right)$, normalised friction ratio $\left(\Delta F_{\mathrm{R}}\right)$ and pore pressure ratio $\left(\Delta B_{\mathrm{q}}\right)$

$$
\Delta I_{\mathrm{c}}=\frac{\partial I_{\mathrm{c}}}{\partial Q_{\mathrm{t}}} \Delta Q_{\mathrm{t}}+\frac{\partial I_{\mathrm{c}}}{\partial F_{\mathrm{R}}} \Delta F_{\mathrm{R}}+\frac{\partial I_{\mathrm{c}}}{\partial B_{\mathrm{q}}} \Delta B_{\mathrm{q}}
$$

in which

$$
\begin{aligned}
\frac{\partial I_{\mathrm{c}}}{\partial Q_{\mathrm{t}}}= & \left(\left\{3-\log \left[Q_{\mathrm{t}}\left(1-B_{\mathrm{q}}\right)\right]\right\}^{2}+\left[1 \cdot 5+1 \cdot 3\left(\log F_{\mathrm{R}}\right)\right]^{2}\right)^{1 / 2} \\
& \times\left\{3-\log \left[Q_{\mathrm{t}}\left(1-B_{\mathrm{q}}\right)\right]\right\} \frac{-1}{Q_{\mathrm{t}} \ln 10}
\end{aligned}
$$

$$
\begin{aligned}
\frac{\partial I_{\mathrm{c}}}{\partial F_{\mathrm{R}}}= & \left(\left\{3-\log \left[Q_{\mathrm{t}}\left(1-B_{\mathrm{q}}\right)\right]\right\}^{2}+\left[1 \cdot 5+1 \cdot 3\left(\log F_{\mathrm{R}}\right)\right]^{2}\right)^{1 / 2} \\
& \times\left[1 \cdot 5+1 \cdot 3\left(\log F_{\mathrm{R}}\right)\right] \frac{1 \cdot 3}{F_{\mathrm{R}} \ln 10}
\end{aligned}
$$

$$
\begin{aligned}
\frac{\partial I_{\mathrm{c}}}{\partial B_{\mathrm{q}}}= & \left(\left\{3-\log \left[Q_{\mathrm{t}}\left(1-B_{\mathrm{q}}\right)\right]\right\}^{2}+\left[1 \cdot 5+1 \cdot 3\left(\log F_{\mathrm{R}}\right)\right]^{2}\right)^{1 / 2} \\
& \times\left\{3-\log \left[Q_{\mathrm{t}}\left(1-B_{\mathrm{q}}\right)\right]\right\} \frac{1}{\ln 10} \frac{1}{1-B_{\mathrm{q}}}
\end{aligned}
$$

The change in soil classification index with the only change in normalised cone resistance (assuming the changes in $F_{\mathrm{R}}$ and $B_{\mathrm{q}}$ are zero) can then be expressed as

$$
\frac{\Delta I_{\mathrm{c}} / I_{\mathrm{c}}}{\Delta Q_{\mathrm{t}} / Q_{\mathrm{t}}}=\frac{\log \left[Q_{\mathrm{t}}\left(1-B_{\mathrm{q}}\right)\right]-3}{I_{\mathrm{c}}^{2} \ln 10}
$$

Similarly, the change in soil classification index with the only change in normalised friction ratio or pore pressure ratio can be expressed by equations (18) and (19)

$$
\begin{aligned}
& \frac{\Delta I_{\mathrm{c}} / I_{\mathrm{c}}}{\Delta F_{\mathrm{R}} / F_{\mathrm{R}}}=\frac{1 \cdot 3\left[1 \cdot 5+1 \cdot 3\left(\log F_{\mathrm{R}}\right)\right]}{I_{\mathrm{c}}^{2} \ln 10} \\
& \frac{\Delta I_{\mathrm{c}} / I_{\mathrm{c}}}{\Delta B_{\mathrm{q}} / B_{\mathrm{q}}}=\frac{B_{\mathrm{q}}\left\{3-\log \left[Q_{\mathrm{t}}\left(1-B_{\mathrm{q}}\right)\right]\right\}}{\left(1-B_{\mathrm{q}}\right) I_{\mathrm{c}}^{2} \ln 10}
\end{aligned}
$$

Equations (17)-(19) quantify the relative change of soil classification index with a relative change in cone penetration resistance, sleeve friction or pore pressure. A ratio smaller than 1 indicates that the magnitude of change in the soil classification system is smaller than the magnitude of change in the measured $q_{\mathrm{c}}, f_{\mathrm{s}}$ and $u$, which means that uncertainties in the predictions of these parameters are filtered by the soil classification index as described by equation (12). Furthermore, the uncertainty in the soil classification index can be filtered by the soil classification system, as indicated by Table 1 . For example, if a variation of $5 \%$ in $\Delta I_{\mathrm{c}} / I_{\mathrm{c}}$ occurs for $I_{\mathrm{c}}$ of $3 \cdot 02, I_{\mathrm{c}}$ can then vary from $2 \cdot 87$ to $3 \cdot 17$. However, any value in this range is classified as clay (see Table 1). This soil classification system further filters the uncertainty in the soil classification index.

\section{CASE STUDY}

In total, 26 CPTU tests (as shown in Fig. 1) have been performed on a soft clay site near the town of Ballina, New South Wales, Australia. The tests were conducted over a total area of $100 \times 100 \mathrm{~m}$. In each test, the cone penetration resistance, sleeve friction and pore pressure were measured 
every $0.02 \mathrm{~m}$ in depth. The profiles of the measured $q_{\mathrm{c}}, f_{\mathrm{s}}$ and $u$ of a typical CPTU test are shown in Fig. 2. These parameters at a designated depth can be used to estimate the same parameters at unsampled locations at the same depth, which is the first step towards the identification of soil stratification at unsampled locations. The estimation of these parameters and their accuracy for a plane at $2 \mathrm{~m}$ depth are first detailed. The uncertainty filtering process is then performed and the soil types at the same plane are predicted. Finally, the soil profile and properties at two unsampled locations, B1 and B2 (also shown in Fig. 1), are examined. B1 is located within the sampling cluster where enough information can be used to evaluate the rationality of the prediction. B2 is far away from the existing CPTU tests and represents a typical prediction where only limited information is available in the field. The accuracy of the predictions from the two locations will be examined separately.

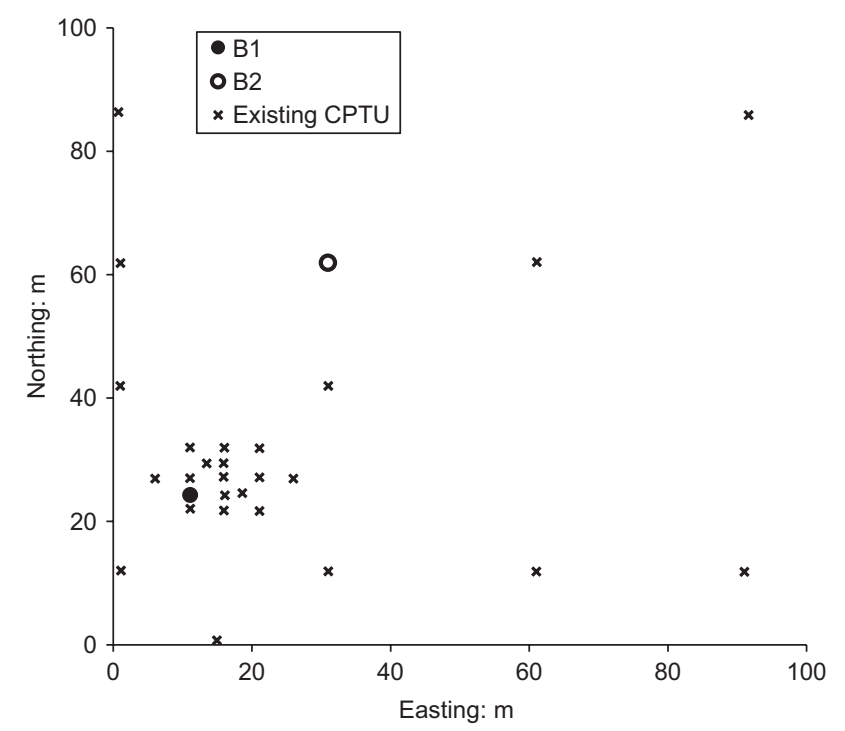

Fig. 1. Locations of existing CPTU tests and unsampled locations (B1 and B2)
Prediction of CPTU parameters at unsampled locations and their accuracy

The cone penetration resistance, sleeve friction and pore pressure measured at $2 \mathrm{~m}$ depth of the $26 \mathrm{CPTU}$ tests are demonstrated in Fig. 3. The vertical axis of the dot points gives the property values, and the vertical lines attached to the points indicate the locations of the tests. The soil at $1.82 \mathrm{~m}$ depth at location $(14.95,0.75)$ is classified as silt mixtures according to the Jefferies \& Davies method (1993). Laboratory sieve analysis of the soil taken at the same location shows that the soil has $43 \cdot 4 \%$ clay, $53 \cdot 6 \%$ silt and $3.0 \%$ sand. Hence the soil is classified as a silt mixture, which is consistent with the classification using the Jefferies \& Davies method (1993). As this method is not the focus of the present study, more discussion on its reliability can be found in, among other sources, the book by Lunne et al. (1997).

Previous researchers have reported that the range of semivariograms in the horizontal direction is larger than that in the vertical direction. The ranges in different directions in a horizontal plane are often assumed the same with an isotropic correlation structure, especially for small data sets (Jernigan, 1986). In this study no direction-dependency is observed among the data in the horizontal plane at a depth of $2 \mathrm{~m}$ (see Fig. 3). Hence a lateral isotropic correlation structure is assumed. Trends which are equal to the averages of the cone penetration resistance, sleeve friction and pore pressure are first removed, respectively. Then the semivariograms of the three parameters are calculated using a self-developed code according to equation (1) and plotted as shown in Fig. 4. Results show that the semivariance increases first with the separation distance and then levels off. A theoretical exponential model is used here to fit the sample semivariogram. For the cone penetration resistance and sleeve friction the model starts from zero, which indicates that the measurement error is negligible. In contrast, the nugget effect in pore pressure is much higher. This means that the measurement error in pore pressure is large, which is consistent with the field observation. The semivariograms for the cone penetration resistance and sleeve friction have small nugget/sill ratios and relatively large ranges, which indicates fairly good semivariograms. However, with the same set of

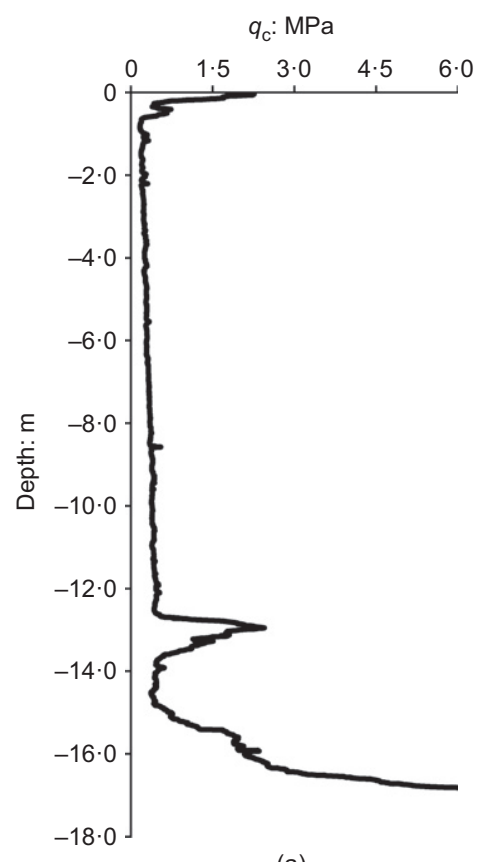

(a)

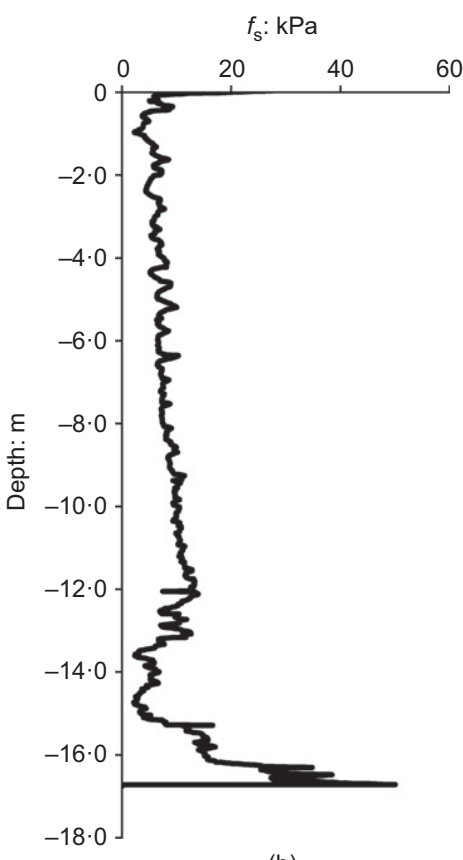

(b)

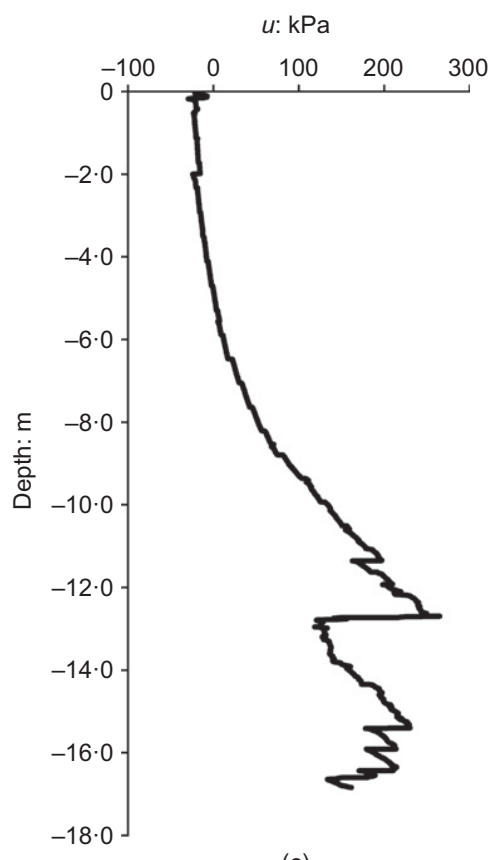

(c)

Fig. 2. Profiles for CPTU test NS 19: (a) cone penetration resistance; (b) sleeve friction; (c) pore pressure 


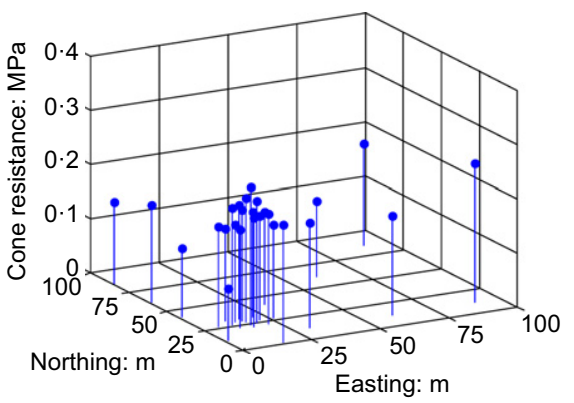

(a)

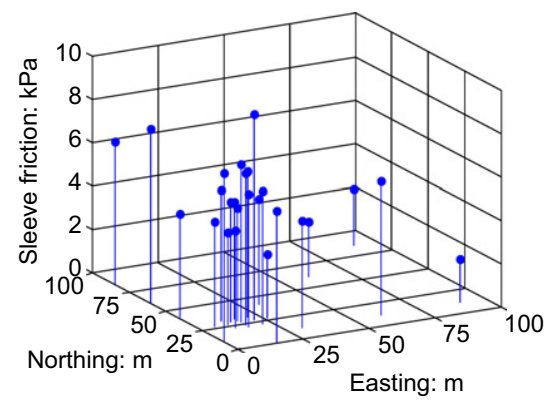

(b)

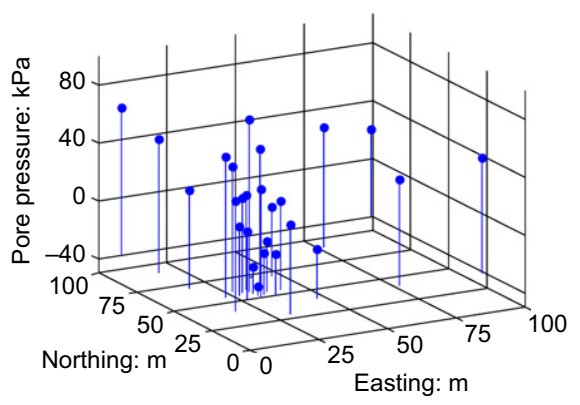

(c)

Fig. 3. Measured (a) cone penetration resistance $\left(q_{\mathrm{c}}\right)$, (b) sleeve friction $\left(f_{\mathrm{s}}\right)$ and (c) pore pressure $(u)$ at $2 \mathrm{~m}$ depth

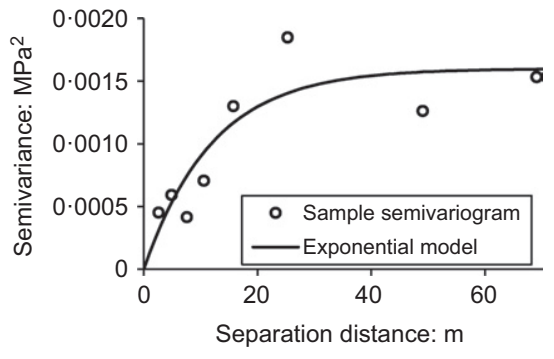

(a)

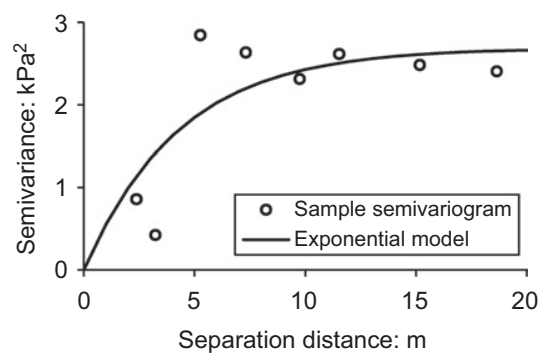

(b)

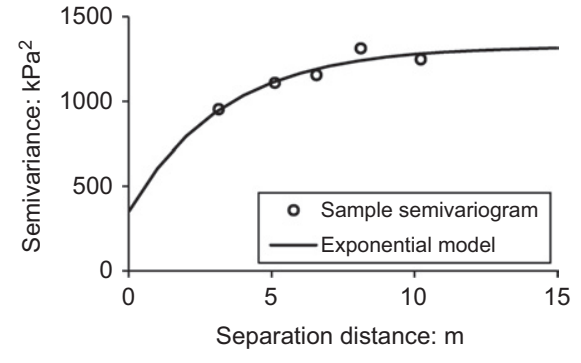

(c)

Fig. 4. Semivariogram for: (a) cone penetration resistance $\left(q_{\mathrm{c}}\right)$; (b) sleeve friction $\left(f_{\mathrm{s}}\right)$; (c) pore pressure (u) at $2 \mathrm{~m}$ depth

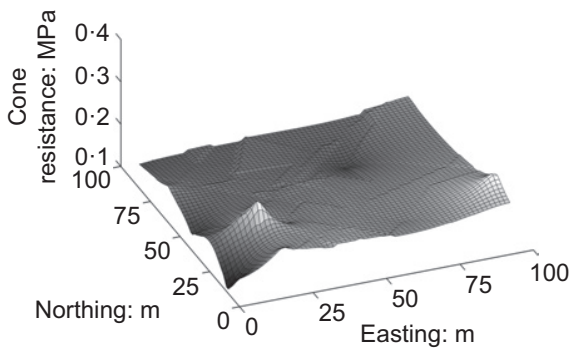

(a)

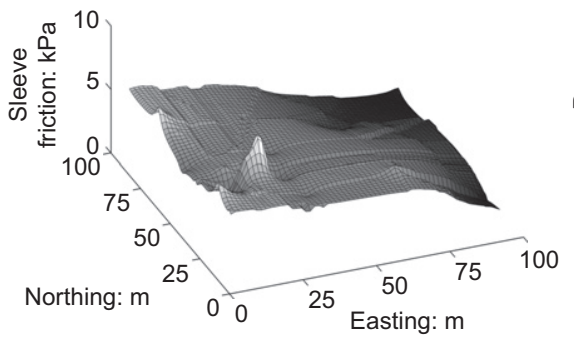

(b)

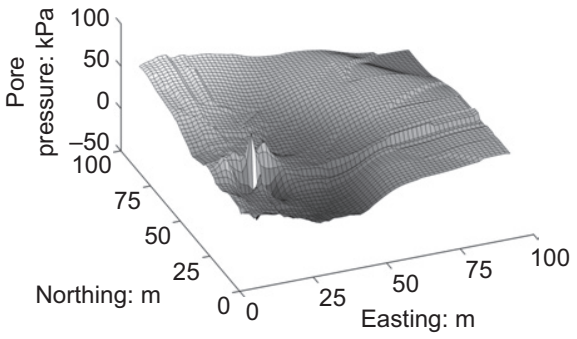

(c)

Fig. 5. Estimated (a) penetration resistance $\left(q_{\mathrm{c}}\right)$, (b) sleeve friction $\left(f_{\mathrm{s}}\right)$ and (c) pore pressure $(u)$ at $2 \mathrm{~m}$ depth

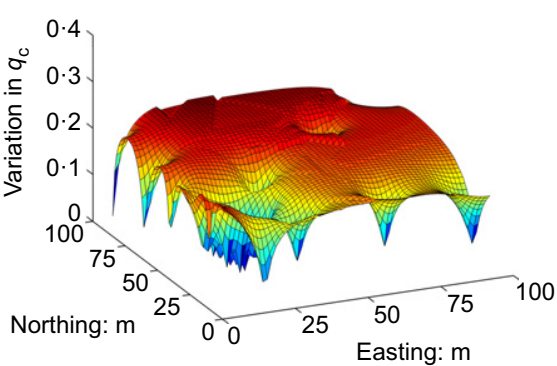

(a)

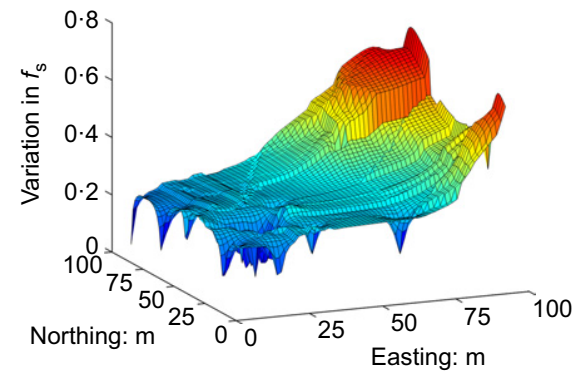

(b)

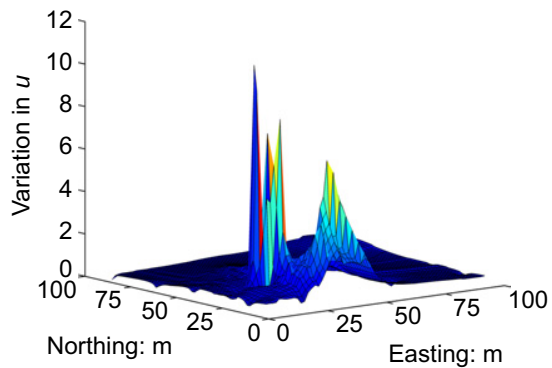

(c)

Fig. 6. Kriging variation of (a) penetration resistance; (b) sleeve friction; and (c) pore pressure at $2 \mathrm{~m}$ depth

data the quality of the semivariogram for the pore pressure is unsatisfactory. The influence of the quality of the semivariogram on the estimation will be further discussed in the following sections.

The Kriging interpolation was performed, which results in the estimated $q_{\mathrm{c}}, f_{\mathrm{s}}$ and $u$ values at $2 \mathrm{~m}$ depth, as shown in Fig. 5. The accuracy of this estimation can be evaluated by the Kriging variation, as defined by equation (5). The Kriging variation values of $q_{\mathrm{c}}, f_{\mathrm{s}}$ and $u$ for unsampled locations at $2 \mathrm{~m}$ depth are shown in Fig. 6. The variations in cone penetration resistance are smaller than $0 \cdot 27$. In particular, the variations are extremely low at locations near the existing CPTs (see Fig. 6(a)). The variations in sleeve friction are relatively large (a maximum variation of $0 \cdot 74$ ), especially in the areas with sparse CPT tests (Fig. 6(b)). The variations in pore pressure are extremely large (a maximum variation of 11 ) in the areas with small pore pressures (Fig. 6(c)). Such large variation is partly due to the poor quality in the 
Table 2. Predicted value, standard error and $95 \%$ confidence interval of $q_{\mathrm{c}}, f_{\mathrm{s}}, u$ at locations B1 and B2

\begin{tabular}{|c|c|c|c|c|c|c|}
\hline \multirow[t]{2}{*}{ Parameters } & \multicolumn{3}{|c|}{ Location B1 } & \multicolumn{3}{|c|}{ Location B2 } \\
\hline & Estimator & Standard error & $95 \% \mathrm{CI}$ & Estimator & Standard error & $95 \% \mathrm{CI}$ \\
\hline $\begin{array}{l}\text { Cone penetration resistance, } q_{\mathrm{c}}: \mathrm{MPa} \\
\text { Sleeve friction, } f_{\mathrm{s}}: \mathrm{kPa} \\
\text { Pore pressure, } u: \mathrm{kPa}\end{array}$ & $\begin{array}{l}0 \cdot 202 \\
4 \cdot 85 \\
18 \cdot 64\end{array}$ & $\begin{array}{l}0 \cdot 019 \\
1 \cdot 24 \\
23 \cdot 15\end{array}$ & $\begin{array}{c}{[0 \cdot 165,0 \cdot 238]} \\
{[2 \cdot 41,7 \cdot 29]} \\
{[-26 \cdot 72,64 \cdot 00]}\end{array}$ & $\begin{array}{l}0 \cdot 171 \\
5 \cdot 22 \\
40 \cdot 53\end{array}$ & $\begin{aligned} 0 \cdot 038 \\
1 \cdot 66 \\
29 \cdot 82\end{aligned}$ & $\begin{array}{c}{[0 \cdot 096,0 \cdot 246]} \\
{[1 \cdot 97,8 \cdot 48]} \\
{[-17 \cdot 93,98 \cdot 98]}\end{array}$ \\
\hline
\end{tabular}

measurement and semivariogram of pore pressure, which will be analysed further in the following sections.

A confidence interval for each parameter can be estimated using the predicted value and the Kriging variance by equation (6). For example, the predicted cone penetration resistance is $0.202 \mathrm{MPa}$ at location $\mathrm{B} 1$ and $0.171 \mathrm{MPa}$ at location B2. The Kriging standard error is $0.019 \mathrm{MPa}$ at location $\mathrm{B} 1$ and $0.038 \mathrm{MPa}$ at location $\mathrm{B} 2$. A larger standard error occurs at location $\mathrm{B} 2$ because the CPT data around $\mathrm{B} 2$ are sparse. The $95 \%$ confidence intervals are $(0 \cdot 165,0 \cdot 238)$ at location B1 and $(0.096,0.246)$ at location B2. The larger standard error at location $\mathrm{B} 2$ results in a wider confidence interval at this location.

A similar procedure can be performed for sleeve friction and pore pressure. The estimators, standard errors and 95\% confidence intervals (shown as CI on column headings) for locations B1 and B2 are shown in Table 2. The Kriging standard error values for pore pressure are extremely large due to the large variations in pore pressure and the poor semivariogram. Although such large variations lead to wide intervals of pore pressure, the quantification of the variations is one of the strengths of the proposed method.

\section{Soil type}

If the soil parameters (i.e. $q_{\mathrm{c}}, f_{\mathrm{s}}$ and $u$ ) at a certain location are estimated, the soil type at this location can be classified using equation (12). As the soil parameters may be distributed in an interval, the soil type may also vary. An alternative soil type can be obtained using the lower bound values of the $95 \%$ confidence interval for the soil parameters at each location. Similarly, a soil type can be obtained using the upper bound of the confidence interval.

The soil classification index, $I_{\mathrm{c}}$, for location B1 calculated from the estimator is 3.02 . The soil classification index is $2 \cdot 86$ using the lower bound value of cone penetration resistance $(0 \cdot 165 \mathrm{MPa})$, sleeve friction $(2.41 \mathrm{kPa})$ and pore pressure $(-26.72 \mathrm{kPa})$. The soil classification index is 3.09 using the upper bound value of cone penetration resistance $(0 \cdot 238 \mathrm{MPa})$, sleeve friction $(7 \cdot 29 \mathrm{kPa})$ and pore pressure $(64.00 \mathrm{kPa})$. Hence the uncertainties in the measured CPTU data lead to a range of soil classification index values from $2 \cdot 86$ to $3 \cdot 09$. A poor quality of data with large uncertainties will result in a wide range of the soil classification index. The variations that propagate from the estimated soil parameters to the soil classification index can be calculated using equations (17) and (18). The variations in the estimated $q_{\mathrm{c}}, f_{\mathrm{s}}$ and $u$ are $0 \cdot 09,0 \cdot 26$ and $1 \cdot 24$, respectively. The variations in $I_{c}$ caused by those in $q_{\mathrm{c}}, f_{\mathrm{s}}$ and $u$ are $0.009,0.034$ and 0.062 , respectively. The variations in $I_{\mathrm{c}}$ are only approximately $10 \%$ of the variations in $q_{\mathrm{c}}, f_{\mathrm{s}}$ and $u$, which indicates that the majority of the uncertainties in the predicted $q_{\mathrm{c}}, f_{\mathrm{s}}$ and $u$ are filtered.

The soil type can be classified by the soil classification index according to Table 1 . When the soil classification index is larger than $2 \cdot 82$ and smaller than $3 \cdot 22$, the soil is classified as a clay. The soil classification index at location B1 is in the range of $2 \cdot 86-3 \cdot 09$, which indicates that the soil is clay. In other words, with $95 \%$ probability, the soil at location $\mathrm{B} 1$ at
$2 \mathrm{~m}$ depth is clay. This process shows that the relatively small variations in the soil classification index are further filtered by the soil classification systems, which leads to a consistent conclusion of clay at unsampled location B1. Although the variations in the estimated $q_{\mathrm{c}}, f_{\mathrm{s}}$ and $u$ are large, the classification of soil type consistently indicates that the soil is clay. Such uncertainty filtering gives a clear indicator of the soil type with high confidence.

At location B2, the soil classification index at $2 \mathrm{~m}$ depth is $3 \cdot 22$, which is on the boundary of clay and organic clay. The soil classification index calculated from the lower bound values of the parameters is $3 \cdot 27$, which indicates that the soil behaves like organic clay. The soil classification index calculated from the upper bound values is $3 \cdot 17$, which is classified as clay. The results indicate that the soil at location $\mathrm{B} 2$ at $2 \mathrm{~m}$ depth may situate in a transition zone from clay to organic clay. The transition may be due to

(a) soil behaviour, which is influenced by the soil ahead and behind the cone tip (Ahmadi \& Robertson, 2005)

(b) the variation in soil classification (e.g. the variations in the soil classification index, $I_{\mathrm{c}}$, caused by variations in $q_{\mathrm{c}}, f_{\mathrm{s}}$ and $u$ are $0.02,0.04$ and 0.02 , respectively; only limited influence is caused by such small variations)

(c) soil located in a transition zone that consists of mixtures of clay and organic clay. The presence of a transition zone can be further examined by the neighbouring CPTs around location B2. The nearest neighbouring CPT tests are NS12, NS28 and NS30. The soils at $2 \mathrm{~m}$ depth at NS12, NS28 and NS30 are clay, organic clay and organic clay, respectively, which confirms that B2 is located in a transition zone from clay to organic clay from south to north.

\section{Soil stratification}

Soil stratification in the horizontal direction. Soil stratification in the horizontal direction can be examined by exploring the soil types at a horizontal plane. The soil types of the whole site at $2 \mathrm{~m}$ depth are calculated for each small zone $(1.5 \times 1.5 \mathrm{~m})$ using the aforementioned method. Fig. 7(a) shows a soil type map that is classified based on the estimated cone penetration resistance, sleeve friction and pore pressure. Organic clay behaviour is present at the west of this area, which changes to clay towards the east and further to silt mixtures at the southeast corner of the site. The soil at location $(14.95,0 \cdot 75)$ is classified as clay in this predicted soil type map. The particle size distribution at this location at $2.27 \mathrm{~m}$ depth shows that there is $54 \cdot 7 \%$ of clay, $41 \cdot 3 \%$ of silt and $4 \%$ of sand. Therefore, the soil particle size distribution also indicates that this is fine-grained soil (i.e. silty clay).

Different soil types may be present due to variations in the estimated soil parameters. For example, the soil types classified using the lower bound and upper bound values of the $95 \%$ confidence interval are not exactly the same as those in Fig. 7(a). Therefore, three soil types at each location are predicted using the estimator, the lower bound and the upper bound of the soil parameters, respectively. By randomly 


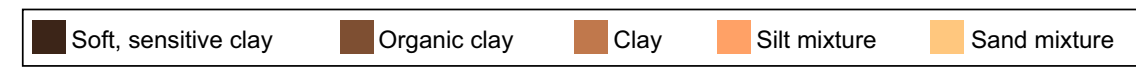

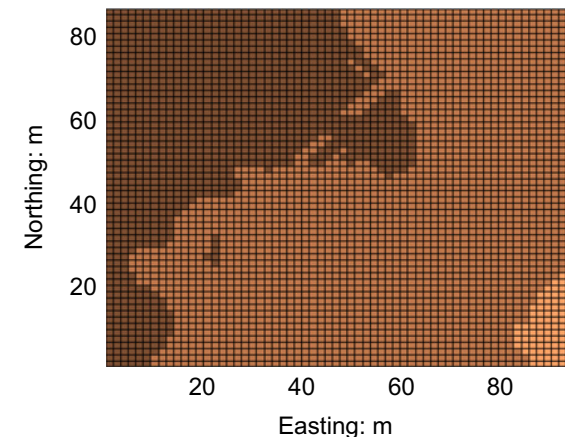

(a)

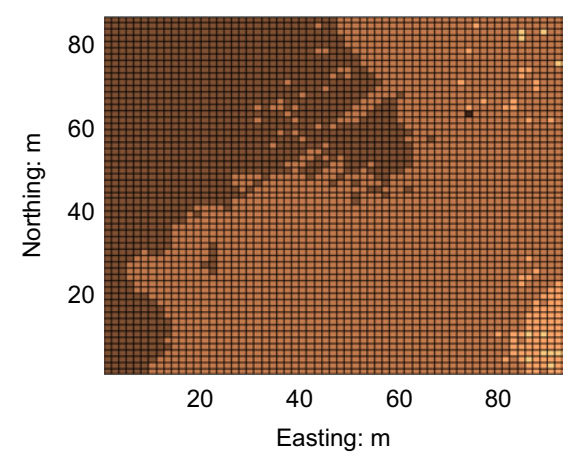

(d)

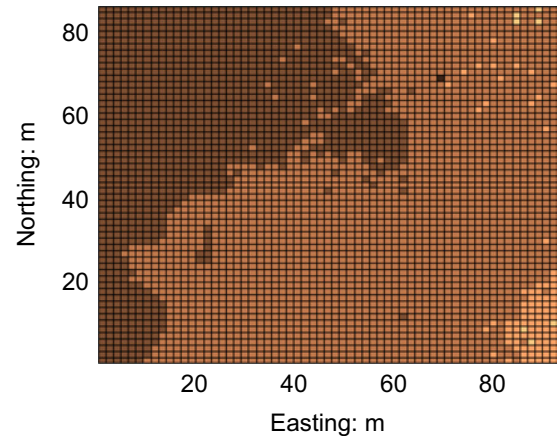

(b)

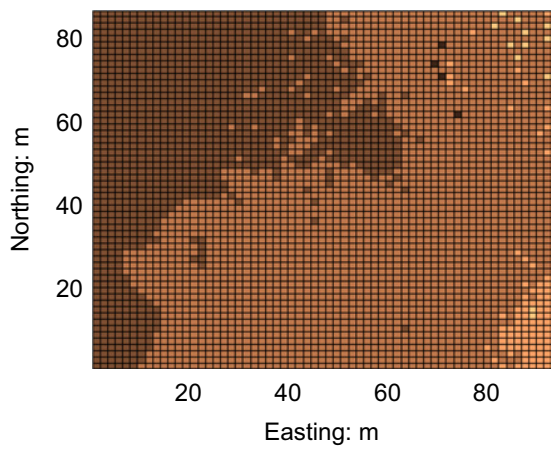

(e)

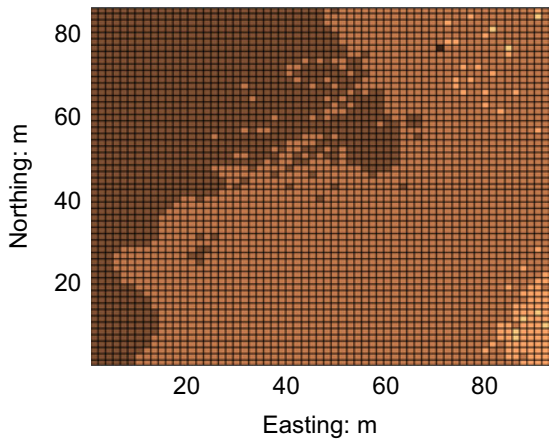

(c)

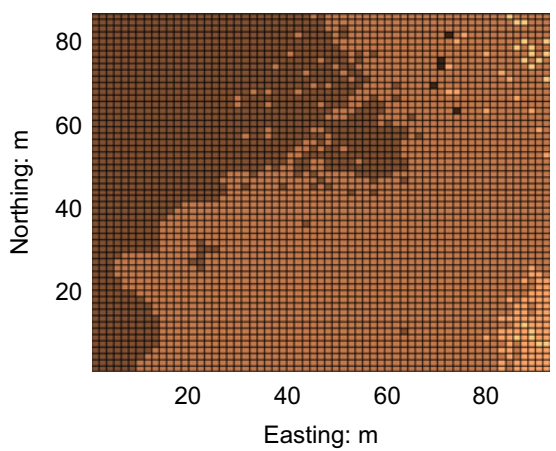

(f)

Fig. 7. Interpreted soil type maps at 2 m depth: (a) from predicted parameters; (b) sampling 1; (c) sampling 2; (d) sampling 3; (e) sampling 4; (f) sampling 5
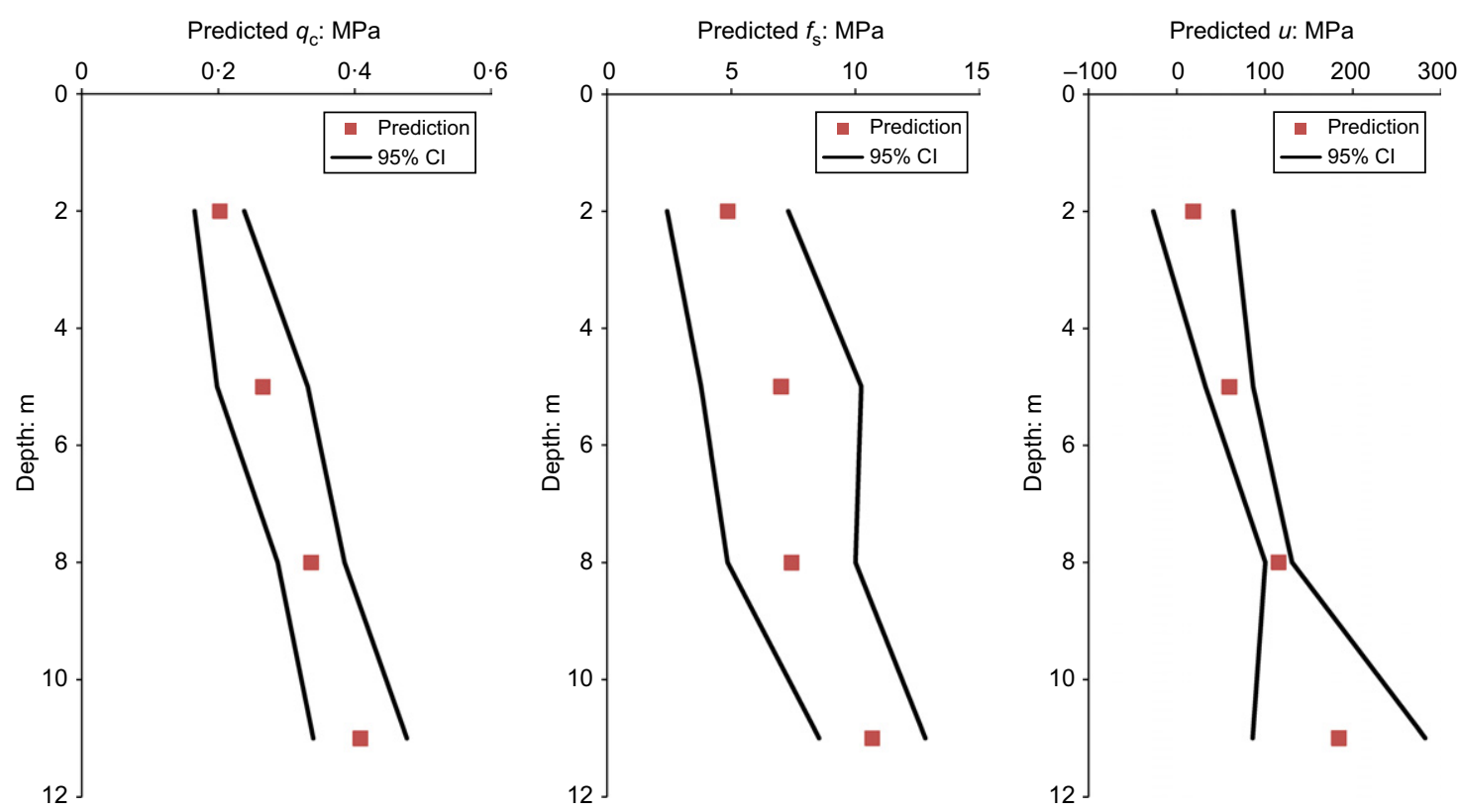

Fig. 8. Estimated value and 95\% confidence intervals at location B1: (a) penetration resistance; (b) sleeve friction; (c) pore pressure

sampling the soil type from the three classifications that reflect the variation in the soil parameters, different soil type maps can be obtained. Figs 7(b)-7(f) show five random samples, which demonstrate the possible presence of soft, sensitive clay, silt mixture and sand mixture in the northeast of the site. The soil type maps show a consistent transition trend, despite the large variations in the estimated $q_{\mathrm{c}}, f_{\mathrm{s}}$ and $u$. The boundary between different soil types is vague when considering the variation in estimation.
Soil profile in the vertical direction. The soil profile in the vertical direction is examined at locations B1 and B2 in this section. Values of the cone penetration resistance, sleeve friction and pore pressure at 2, 5, 8 and $11 \mathrm{~m}$ depths are first estimated for location $\mathrm{B} 1$. The estimated values and $95 \%$ confidence intervals of $q_{\mathrm{c}}, f_{\mathrm{s}}$ and $u$ are shown in Fig. 8. Considerable variations are present in these parameters. Soil classification at location B1 is performed and shown in Fig. 9. At $2 \mathrm{~m}$ depth, clay is consistently identified, despite 
considerable variation in the estimated $q_{\mathrm{c}}, f_{\mathrm{s}}$ and $u$. At $5 \mathrm{~m}$ depth, the prediction from the estimator and upper bound values indicate that the soil in this area is clay. However, the classification from the lower bound values of the interval indicates organic clay behaviour. Hence, the soil at $5 \mathrm{~m}$ depth may be in a transition zone from clay to organic clay. At $8 \mathrm{~m}$ depth, the estimator and the lower bound values lead to the conclusion of organic clay. The upper bound values identify the soil as clay, which further confirms the presence of a transition zone from clay to organic clay. At $11 \mathrm{~m}$ depth, all of the estimators, lower bound values and upper bound

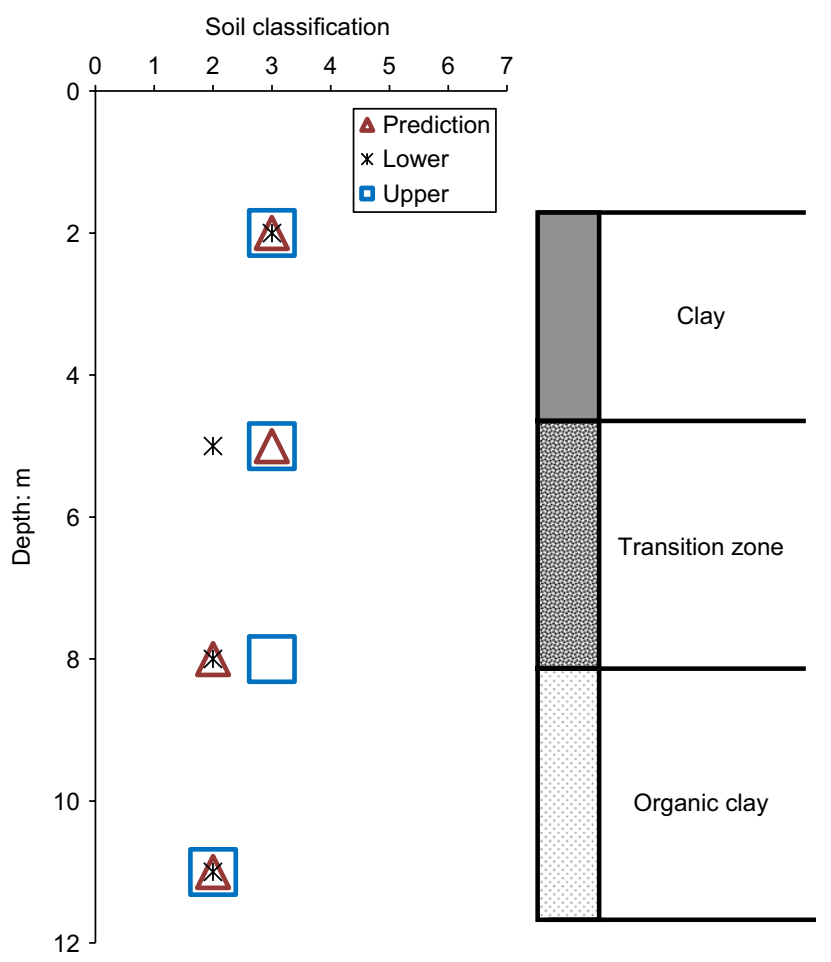

Fig. 9. Soil classification and stratification at location B1 values of the $95 \%$ confidence interval indicate that the soil behaves as organic clay.

These results indicate clear soil stratification at location $\mathrm{B} 1$, which is clay at $2 \mathrm{~m}$ depth, transitioning to organic clay at $11 \mathrm{~m}$ depth. This estimation can be examined by comparing the stratification at location B1 with neighbouring tests (see Fig. 10). CPT test NS14 is located approximately $2 \mathrm{~m}$ south of B1. NS15 is located $3 \mathrm{~m}$ north of B1. NS 19 is located $5 \mathrm{~m}$ east of B1. The stratification of the three existing CPT tests and the soil types at 2, 5,8 and $11 \mathrm{~m}$ are clearly demonstrated in the figure. The soils at $2 \mathrm{~m}$ depth at the three locations are all clay, which supports the conclusion that the soil at B1 is clay. At $5 \mathrm{~m}$ depth, the soil at NS15 is in a transition zone, and the soils at NS14 and NS19 are clay, which also indicate that a transition zone at B1 is possible. At $8 \mathrm{~m}$ depth, the soil in NS19 is clay. The soils in NS15 and NS14 are located in the transition zone. Hence, with a high probability, location B1 is situated in a transition zone. At $11 \mathrm{~m}$ depth, the soils in the three CPT tests are all organic clay. Organic clay at $11 \mathrm{~m}$ depth at location B1 is logical. The boundary of the stratification can be accurately identified if predictions are obtained at more depths.

Figure 11 shows the estimators and 95\% confidence intervals of $q_{\mathrm{c}}, f_{\mathrm{s}}$ and $u$ at location $\mathrm{B} 2$. The variations in the three parameters at location B2 are larger than those at location B1. The soil types classified from the estimator, the lower bound and upper bound values of the confidence interval are shown in Fig. 12. In the upper $2 \mathrm{~m}$, the soil varies from clay to organic clay. From approximately $5 \mathrm{~m}$, the prediction from the estimator and the $95 \%$ confidence interval consistently indicate that the soil behaves like organic clay. Hence, a layer of organic clay from 5 to $11 \mathrm{~m}$ can be concluded with high confidence.

\section{Soil properties}

With a clear definition of soil stratification, the property of each layer of soil can be established. Here, the layer of organic clay at location B2 is used as an example. The undrained shear strength, $s_{\mathrm{u}}$, of clay can be calculated based on CPTU tests as

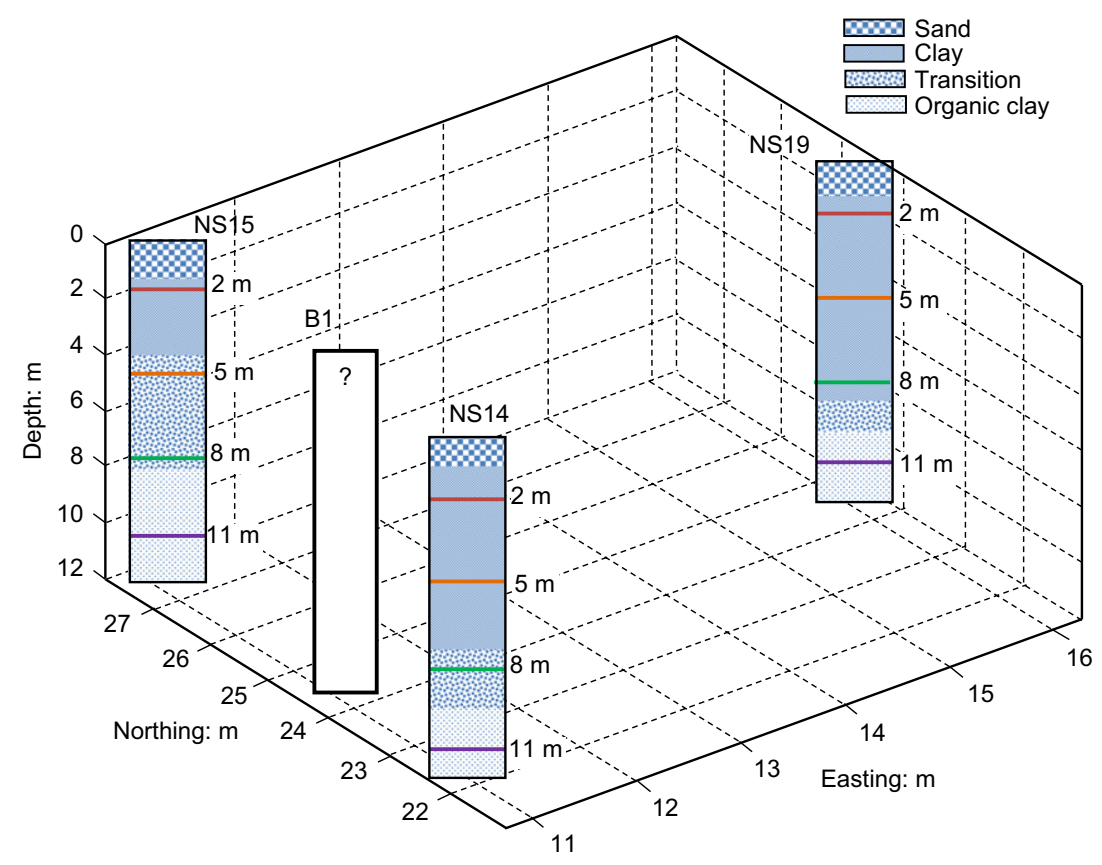

Fig. 10. Comparison of soil strata at unsampled location B1 with neighbouring CPT tests 

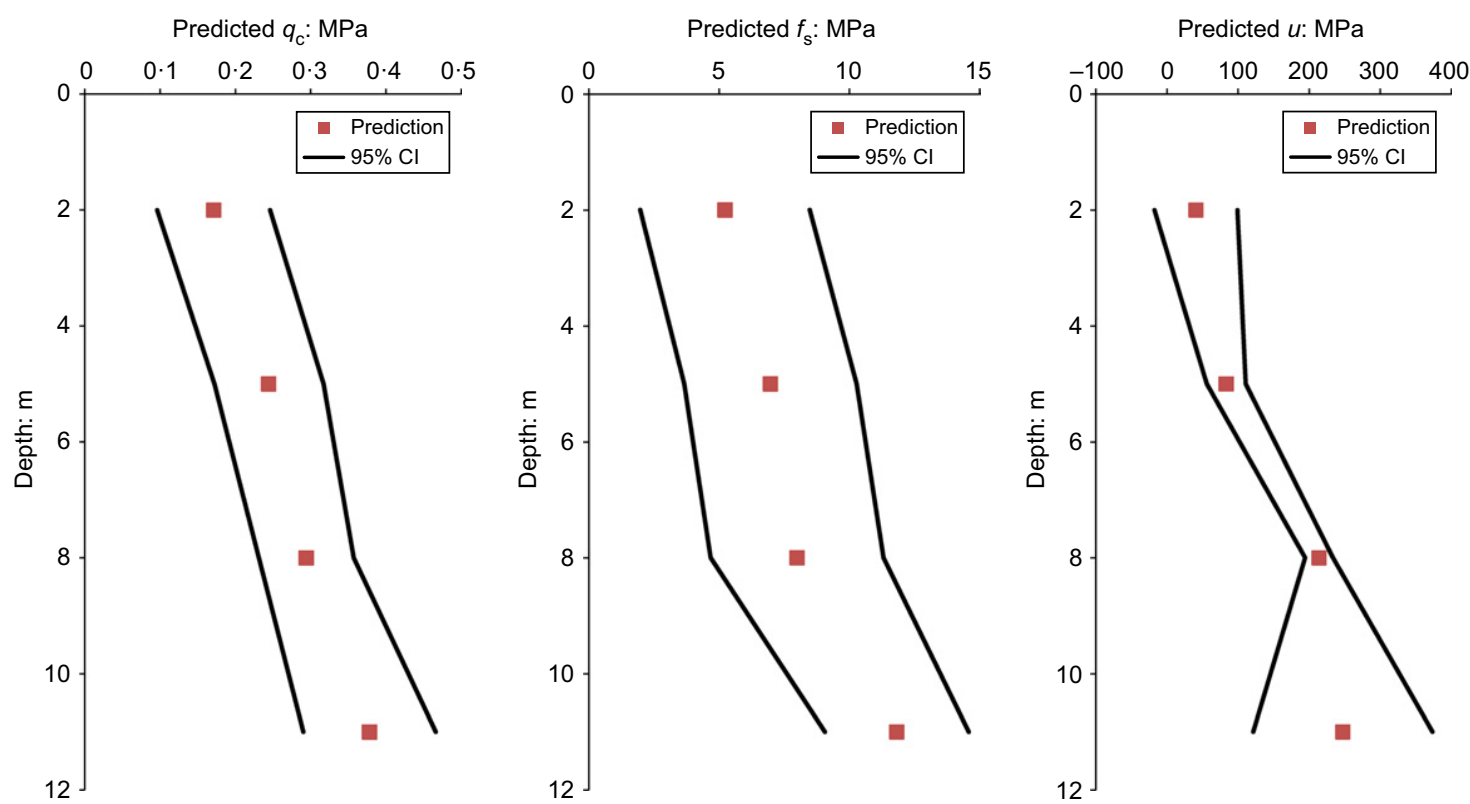

Fig. 11. Estimated value and 95\% confidence intervals at location B2: (a) penetration resistance; (b) sleeve friction; (c) pore pressure

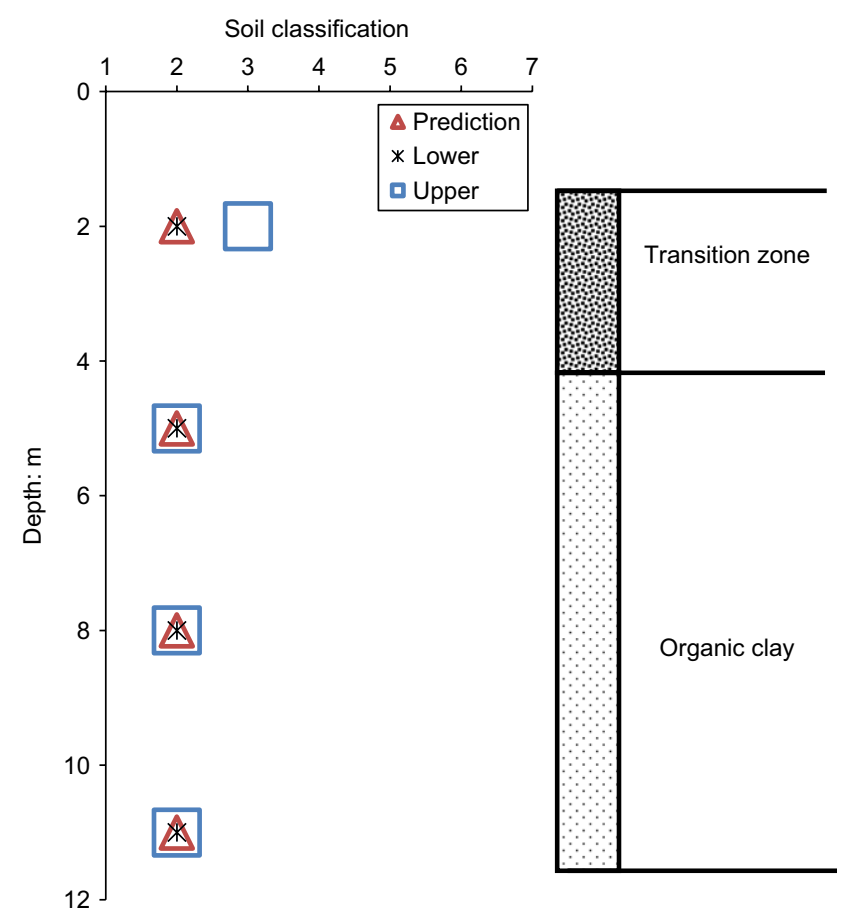

Fig. 12. Soil classification and stratification at location $B 2$

$$
s_{\mathrm{u}}=\frac{q_{\mathrm{t}}-\sigma_{\mathrm{v} 0}}{N_{\mathrm{c}}}
$$

where $N_{\mathrm{c}}$ is a cone factor. The cone factor values typically range from 7 to 15 (Robertson \& Campanella, 1983), depending on the sensitivity and the overconsolidation ratio of the clay. Although affecting the absolute value of shear strength, the cone factor does not affect the trend of the strength. Kelly et al. (2014) have calibrated the cone factor for the Ballina clay relative to laboratory triaxial compression strength, which results in $N_{\mathrm{c}}=11 \cdot 2$.

Parameters $q_{\mathrm{c}}, f_{\mathrm{s}}$ and $u$ are first estimated using the Kriging technique at various depths, which are further used to derive the corrected penetration resistance, $q_{\mathrm{t}}$, according to equation (10). The profile of corrected cone penetration resistance for the layer of organic clay (from 5 to $11 \mathrm{~m}$ ) at

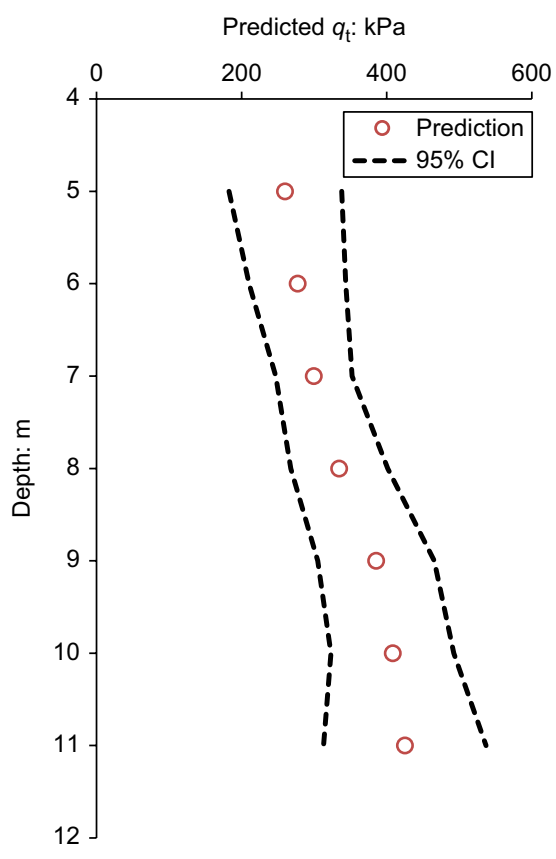

Fig. 13. Corrected tip resistance $\left(q_{t}\right)$ of the organic clay layer at location B2

location B2 is shown in Fig. 13. The cone penetration resistance increases with depth. The range of cone penetration resistance with $95 \%$ probability is also given in Fig. 13. The shear strength of this organic clay layer can then be obtained using equation (20). The estimated shear strength and its 95\% confidence interval along the depth are shown in Fig. 14. The undrained shear strength increases almost linearly with depth. The strength profile in this layer is estimated by $s_{\mathrm{u}}=8.0+1.5 z \mathrm{kPa}$, with a strength of $15.5 \mathrm{kPa}$ at the layer surface (i.e. $5 \mathrm{~m}$ ) and a gradient of $1.5 \mathrm{kPa} / \mathrm{m}$.

\section{CONCLUSIONS}

A method has been developed for the prediction of soil stratification at unsampled locations. The strength of this method is in its ability to greatly filter the uncertainties in 


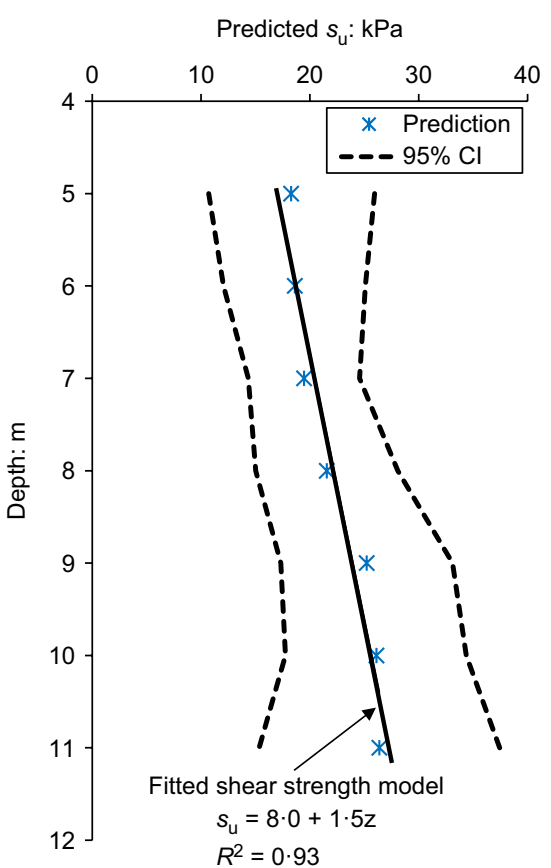

Fig. 14. Shear strength and $95 \%$ confidence interval of the organic clay layer at location B2

prediction in an explicit manner, which leads to clear stratification with a high degree of confidence. The resulting soil types and stratification were validated against existing CPTU tests. Excellent agreement was obtained between the predicted stratification and that based on sampling and sieve analysis.

Equations were derived to quantify the degree of uncertainties reduced by the proposed method. The majority of the uncertainties in the soil parameters (i.e., $q_{\mathrm{c}}, f_{\mathrm{s}}$ and $u$ ) are screened by the soil classification index. The remaining uncertainties are further filtered by the use of a soil classification system. This method leads to a consistent conclusion on soil type, despite considerable variations in soil parameters. Better prediction accuracy can be obtained for CPTU data of higher quality, better correlation of existing data and locations closer to existing tests.

Another advantage of this method is that the soil properties at locations without CPTU tests can be estimated at various depths with high confidence (and with confidence intervals calculated). The undrained soil strength profile of an organic clay layer at an unsampled location was found to increase linearly with soil depth, with a strength of $15.5 \mathrm{kPa}$ at the layer surface and a gradient of $1.5 \mathrm{kPa} / \mathrm{m}$ with depth. Although this paper illustrates the procedure using a clay layer, the method is equally applicable to sand layers.

\section{ACKNOWLEDGEMENTS}

This research was supported by the Australian Research Council Centre of Excellence for Geotechnical Science and Engineering and by the Lloyd's Register Foundation. This support is gratefully acknowledged.

\section{NOTATION}

$a$ net area ratio

$B_{\mathrm{q}}$ pore pressure ratio

$F_{\mathrm{R}}$ normalised friction ratio

$f_{\mathrm{s}}$ sleeve friction

$h$ separation distance

$I_{\mathrm{c}}$ soil classification index $m$ Lagrange multiplier

$N_{\mathrm{c}} \quad$ cone factor

$p_{i} \quad$ property value at location $i$

$p_{i+h} \quad$ property value at location $i+h$

$\hat{p}_{0}$ estimated property at the unsampled location

$\left\langle p_{0}\right\rangle_{1-\alpha} \quad(1-\alpha)$ confidence interval

$Q_{\mathrm{t}}$ normalised cone resistance

$q_{\mathrm{c}}$ measured cone penetration resistance

$q_{\mathrm{t}}$ corrected cone penetration resistance

$s_{\mathrm{u}} \quad$ undrained shear strength

$u$ pore pressure

$u_{0} \quad$ equilibrium pore pressure

$\gamma_{h} \quad$ semivariogram value for the data pairs with property values of $p_{i}$ and $p_{i+h}$

$\varepsilon \quad$ Kriging variation

$\lambda_{i} \quad$ weight for measured property $p_{i}$

$\sigma \quad$ Kriging standard error

$\sigma_{\mathrm{v} 0}$ total overburden stress

$\sigma_{\mathrm{v} 0}^{\prime} \quad$ effective overburden stress

$\Phi$ cumulative distribution function of standard normal variate

\section{REFERENCES}

Ahmadi, M. M. \& Robertson, P. K. (2005). Thin layer effects on the CPT $q_{\mathrm{c}}$ measurement. Can. Geotech. J. 42, No. 5, 1302-1307.

Ang, A. H. S. \& Tang, W. H. (2007). Probability concepts in engineering: emphasis on applications in civil and environmental engineering. New York, NY, USA: Wiley.

Beacher, G. B. \& Christian, J. T. (2003). Reliability and statistics in geotechnical engineering. Chichester, UK: John Wiley \& Sons.

Burd, H. J. \& Frydman, S. (1997). Bearing capacity of plane-strain footings on layered soils. Can. Geotech. J. 34, No. 2, 241-253.

CEN (European Committee for Standardization) (2002). EN 1990: Eurocode - Basis of structural design. Brussels, Belgium: European Committee for Standardization.

Cetin, K. O. \& Ozan, C. (2009). CPT-based probabilistic soil characterization and classification. J. Geotech. Geoenvir. Engng 135, No. 7, 84-107.

Chilès, J. P. \& Delfiner, P. (2012). Geostatistics: modeling spatial uncertainty. New York, NY, USA: John Wiley \& Sons, Inc.

Das, B. M. (2010). Principles of geotechnical engineering, 7th edn. Stamford, CT, USA: Cengage Learning.

Dasaka, S. M. \& Zhang, L. M. (2012). Spatial variability of in situ weathered soil. Géotechnique 62, No. 5, 375-384, http://dx.doi. org/10.1680/geot.8.P.151.3786.

Douglas, B. J. \& Olsen, R. S. (1981). Soil classification using electric cone penetrometer. In Proceedings of the symposium on cone penetration testing and experience, St Louis, MO, USA (eds G. M. Norris and R. D. Holtz), pp. 209-227. New York, NY, USA: American Society of Civil Engineers.

Eslami, A. \& Fellenius, B. H. (1997). Pile capacity by direct CPT and CPTu methods applied to 102 case histories. Can. Geotech. J. 34, No. 6, 886-904.

Houlsby, N. M. T. \& Houlsby, G. T. (2013). Statistical fitting of undrained strength data. Géotechnique 63, No. 14, 1253-1263, http://dx.doi.org/10.1680/geot.13.P.007.

Huang, J. \& Griffiths, D. V. (2010). One-dimensional consolidation theories for layered soil and coupled and uncoupled solutions by the finite-element method. Géotechnique 60, No. 9, 709-713, http://dx.doi.org/10.1680/geot.08.P.038.

Jefferies, M. G. \& Davies, M. P. (1993). Use of CPTU to estimate equivalent SPT N60. Geotech. Test. J. 16, No. 4, 458-468.

Jernigan, R. W. (1986). A primer on Kriging. Washington, DC, USA: Environmental Protection Agency.

Jung, B. C., Gardoni, P. \& Biscontin, G. (2008). Probabilistic soil identification based on cone penetration tests. Géotechnique 58, No. 7, 591-603, http://dx.doi.org/10.1680/geot.2008.58. 7.591.

Kelly, R., O’Loughlin, C. D., Bates, L., Gourvenec, S. M., Colreavy, C., White, D. J., Gaone, F. M., Doherty, J. P. \& Randolph, M. F. (2014). In situ testing at the National Soft Soil Field Testing Facility, Ballina, New South Wales. Australian Geomech. 49, No. $4,15-28$. 
Kulatilake, P. H. S. W. \& Ghosh, A. (1988). An investigation into accuracy of spatial variation estimation using static cone penetration data. Proceedings of the 1st international symposium on penetration testing, Orlando, FL, pp. 815-821.

Kurup, P. U. \& Griffin, E. P. (2006). Prediction of soil composition from CPT data using general regression neural network. J. Comput. Civ. Engng 20, No. 4, 281-289.

Lacasse, S. \& Nadim, F. (1996). Uncertainties in characterizing soil properties. Uncertainty in the geologic environment: from theory to practice (eds C. D. Roth, P. P. Shackelford and M. J. S. Nelson), Geotechnical Special Publication No. 58, pp. 49-75. Reston, VA, USA: American Society of Civil Engineers.

Lee, K. K., Cassidy, M. J. \& Randolph, M. F. (2013). Bearing capacity on sand overlying clay soils: experimental and finite-element investigation of potential punch-through failure. Géotechnique 63, No. 15, 1271-1284, http://dx.doi.org/10.1680/ geot.12.P.176.

Lloret-Cabolt, M., Fenton, G. A. \& Hicks, M. A. (2014). On the estimation of scale of fluctuation in geostatistics. Georisk 8, No. 2, 129-240.

Lunne, T., Robertson, P. K. \& Powell, J. J. M. (1997). Cone penetration testing in geotechnical practice. London, UK: Blackie Academic \& Professional.

Matheron, G. (1971). The theory of regionalized variables and its applications. Paris, France: Les Cahiers du Centre de Morphonogie Mathematique de Fontainebleau, Ecole National Superieure des Mines de Paris.

Murakami, S., Yasuhara, K., Suzuki, K. \& Komine, H. (2006). Reliable land subsidence mapping using a spatial interpolation procedure based on geostatistics. Soils Found. 46, No. 2, $123-134$.

Olea, R. A. (1999). Geostatistics for engineers and earth scientists. Boston, MA, USA: Kluwer Academic.

Olsen, R. S. \& Mitchell, J. K. (1995). CPT stress normalization and prediction of soil classification. Proceedings of international symposium on cone penetration testing, CPT95, Linkoping, Sweden, SGI report 3, vol. 95, no. 2, pp. 257-262.

Padrón, L. A., Aznárez, J. J. \& Maeso, O. (2008). Dynamic analysis of piled foundations in stratified soils by a BEM-FEM model. Soil Dynam. Earthquake Engng 28, No. 5, 333-346.

Robertson, P. K. (1990). Soil classification using the cone penetration test. Can. Geotech. J. 27, No. 1, 151-158.

Robertson, P. K. \& Campanella, R. G. (1983). Interpretation of cone penetration tests. Part II: Clay. Can. Geotech. J. 20, No. 4, 734-745.

Schmertmann, J. H. (1978). Guidelines for cone test, performance, and design, Report FHWA-TS-78209. Washington DC, USA: Federal Highway Administration.

Schneider, J. A., Randolph, M. F., Mayne, P. W. \& Ramsey, N. R. (2008). Analysis of factors influencing soil classification using normalized piezocone tip resistance and pore pressure parameters. J. Geotech. Geoenvir. Engng 134, No. 11, $1569-1586$.

Wang, Y., Huang, K. \& Cao, Z. (2013). Probabilistic identification of underground soil stratification using cone penetration tests. Can. Geotech. J. 50, No. 7, 766-776.

Wang, Y., Huang, K. \& Cao, Z. (2014). Bayesian identification of soil strata in London Clay. Géotechnique 64, No. 3, 239-246, http://dx.doi.org/10.1680/geot.13.T.018.

White, D. J., Westgate, Z. J. \& Tian, Y. (2014). Pipeline lateral buckling: realistic modelling of geotechnical variability and uncertainty. Proceedings of the offshore technology conference, Houston, TX, paper OTC25286.

Zhang, Z. \& Tumay, M. T. (1999). Statistical to fuzzy approach toward CPT soil classification. J. Geotech. Geoenvir. Engng 125, No. 3, 179-186.

Zhang, Z., Huang, M. \& Zhang, M. (2012). Deformation analysis of tunnel excavation below existing pipelines in multi-layered soils based on displacement controlled coupling numerical method. Int. J. Numer. Analyt. Methods Geomech. 36, No. 11, 1440-1460. 